\title{
Indenopyrans - synthesis and photoluminescence properties
}

\author{
Andreea Petronela Diac ${ }^{1}$, Ana-Maria Tepeş ${ }^{1}$, Albert Soran ${ }^{1}$, Ion Grosu ${ }^{1}$, \\ Anamaria Terec ${ }^{1}$, Jean Roncali ${ }^{2}$ and Elena Bogdan ${ }^{* 1}$
}

\author{
Full Research Paper \\ Address: \\ ${ }^{1}$ Babeş-Bolyai University, Center of Supramolecular Organic and \\ Organometallic Chemistry (CSOOMC) Cluj-Napoca, 11 Arany Janos, \\ 400028 Cluj-Napoca, Romania and ${ }^{2}$ Group Linear Conjugated \\ Systems, CNRS Moltech-Anjou, University of Angers, 2 Boulevard \\ Lavoisier 49045 Angers, France \\ Email: \\ Elena Bogdan* - ebogdan@chem.ubbcluj.ro \\ * Corresponding author \\ Keywords: \\ indenopyran-3-ones; organic fluorophores; pyrones; solid-state \\ emission spectra; solution emission spectra; UV-vis spectra
}

\begin{abstract}
New indeno[1,2-c]pyran-3-ones bearing different substituents at the pyran moiety were synthesized and their photophysical properties were investigated. In solution all compounds were found to be blue emitters and the trans isomers exhibited significantly higher fluorescence quantum yields (relative to 9,10-diphenylanthracene) as compared to the corresponding cis isomers. The solid-state fluorescence spectra revealed an important red shift of $\lambda_{\max }$ due to intermolecular interactions in the lattice, along with an emissionband broadening, as compared to the solution fluorescence spectra.
\end{abstract}

\section{Introduction}

Indenopyrans are functionalized oxygen-containing heterocycles consisting of fused indene and pyran units. Generally, oxygen-containing heteroaromatic compounds have been encountered as biologically active molecules and display exciting physico-chemical properties. Therefore, these compounds have found many applications in medicinal chemistry and material sciences. Besides, the annelated cyclic indenes containing $\mathrm{N}$ or $\mathrm{O}$ heteroatoms are the main structural frameworks of several natural alkaloids [1], while indenopyran derivatives were found to be valuable substrates for the synthesis of various compounds with biological activity $[2,3]$. Some indeno[1,2$c$ ]isochromen-5(11H)-ones have been reported as key intermediates for the development of several topoisomerase I (Top1) anticancer agents [4-7]. A natural product exhibiting very prom- ising antitumor activity is $\beta$-lapachone having a naphtho[1,2$b]$ pyrandione skeleton $[8,9]$. Also worth mentioning in this context are benzo $[b]$ indeno-[2,1-e]pyran-10,11-diones, which stimulate the biosynthesis of erythropoietin and are used to treat anemia [10]. Another application includes the use of some amino-spiroindenopyran derivatives as selective sensors for thallium(I) ions in human urine [11].

Pyran-containing derivatives have been found to act as potential candidates for electroluminescent devices due to their fluorescent properties. Fluorescent dyes have lately attracted considerable interest owing to their wide range of applications in various fields. For example, naphthopyrans (e.g. 3,3-diphenyl$3 H$-naphtho[2,1-b]pyrans) are important photochromic com- 
pounds used for the fabrication of plastic lenses [12,13]. Their photochromic properties were improved through an extended conjugation through the fusion to an indeno group. Moreover, 2-alkyl-6-(4-(dimethylaminostyryl)-4H-pyran, 2,3-dihydro- $1 H$ cyclopenta[3a,8a]indolin-5-enyl)-4H-pyran [14-17] and benzopyran (4-dicyanomethylenechromene) $[18,19]$ have been employed as red doping agents for organic light emitting diodes (OLEDs). Furthermore, pyran derivatives decorated with electron-donating 6-(4-diethylamino)phenyl and electron-withdrawing cyano groups have been found to exhibit good solvatochromism properties and high quantum yields in the solid state why they are considered as important precursors for the fabrication of fluorescent materials [20].

Owing to their exciting photophysical properties many dicyanomethylene pyran-containing chromophores are valuable candidates for the fabrication of OLEDs [21,22], dye lasers [23], sensors [24], dye-sensitized solar cells, fluorescent probes [25] or logic gates [26]. Recently [27], 6- $\mathrm{CF}_{3}-2 \mathrm{H}$-pyran-2-ones have been reported as potential building blocks for the preparation of novel trifluoromethylated heterocycles, such as indone and carbostyril derivatives.

Based on their important biological functions in nature and the synthetic potential of $\alpha$-pyrones for the construction of a variety of fluorescent heteroarenes, we decided to synthesize and study the optoelectronic properties of some indeno-fused pyran-3ones and the results are reported herein.

\section{Results and Discussion}

For a long time, the Diels-Alder reaction of simple heterosubstituted 1,3-dienes has been considered a standard procedure to prepare highly functionalized ring systems [28]. Taking advantage of diazalactones to act as the dienophile component in inverse-electron demand Diels-Alder reactions, a series of new dihydroindeno[1,2-c]pyran derivatives was synthesized. Thus, the addition of freshly distilled indene as a diene component to oxadiazinones 1 as the dienophiles [29] under acidic conditions (TFA, TFAA) led to the formation of dihydroindeno[1,2c]pyran-3-ones $\mathbf{2}$ and $\mathbf{3}$ as a mixture of isomers (Scheme 1). Additionally, the corresponding phenyl-substituted compounds $\mathbf{2 a}$ and 3a (previously reported [30]) were synthesized to investigate the effect of an aryl substituent in position 1 on the photophysical properties of the compounds. The selective formation of type 3 isomers has been reported earlier [31,32]. They are accessible through a cycloaddition reaction of indene and methyl 6-oxo-5-phenyl-6H-1,3,4-oxadiazine-2-carboxylate followed by the treatment with bromine (or hydrogen chloride), thus yielding the corresponding halogenated lactones having the 4a,9a-fused skeleton and an ester group at position 1.

The cycloaddition reaction proceeded with moderate regio- and stereoselectivity. As reported in the literature, the inverse-electron demand Diels-Alder cycloaddition of unsymmetrical olefins and oxadiazinones [33-35] may lead to two possible regioisomers: isomer 2 with the benzene ring fused at $\mathrm{C} 5 \mathrm{a}-\mathrm{C} 9 \mathrm{a}$ and its regioisomer 3 with the benzene ring fused at $\mathrm{C} 4 \mathrm{~b}-\mathrm{C} 8 \mathrm{a}$ (Figure 1).

Additionally, due to the new stereocenters created at positions 4 and $4 \mathrm{a}$, each regioisomer could be expressed as a set of diastereoisomers. Thus, the isomers denoted 2' and 3 ' exhibit the phenyl group at position 4 and the indeno fragment at position $4 \mathrm{a}$ in a trans configuration, while the isomers 2 " and 3"

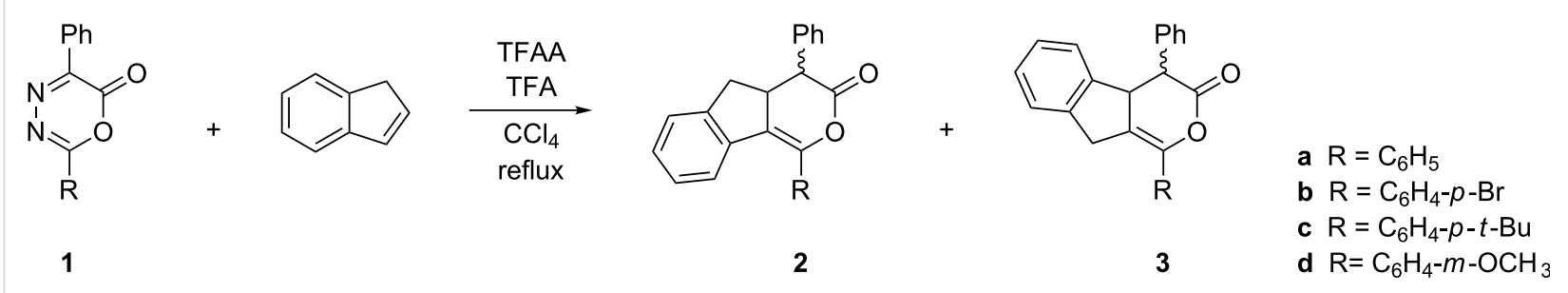

Scheme 1: Synthesis of dihydroindeno[1,2-c]pyran-3-ones 2 and 3.
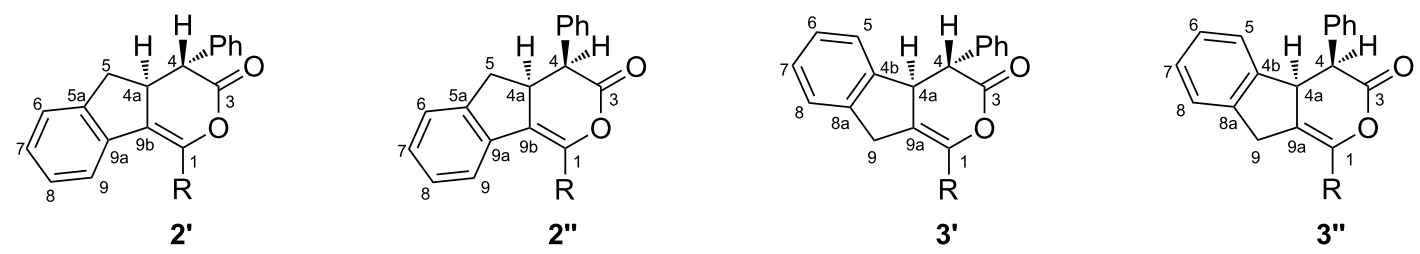

Figure 1: Possible isomers of dihydroindeno[1,2-c]pyran-3-ones 2 and 3. 
bear the two aforementioned groups in a cis configuration (Figure 1).

In most cases, regioisomer 2 predominates and occasionally, formation of derivative $\mathbf{3}$ has not even been observed (e.g., $\mathbf{d}$ derivatives). Moreover, the nature of the substituent influences the regio- and diastereoisomeric ratio (Table 1).

The diastereoisomers exhibit very close $R_{\mathrm{f}}$ values which makes their separation by conventional chromatography quite difficult. Nevertheless, successful separation of diastereoisomers $\mathbf{2}^{\prime}$ and $2 "$ as individual isomers has been achieved for all compounds.

The configuration of the diastereoisomers was assigned based on ${ }^{1} \mathrm{H}$ NMR spectroscopic measurements (Figure 2). Thus, for

\begin{tabular}{|c|c|c|c|c|}
\hline \multirow[b]{2}{*}{ Compound } & \multicolumn{4}{|c|}{ Ratio } \\
\hline & $2^{\prime}$ & 2" & $3^{\prime}$ & 3" \\
\hline a $\mathrm{R}=\mathrm{C}_{6} \mathrm{H}_{5}$ & 1 & - & - & 0.2 \\
\hline b $\mathrm{R}=\mathrm{C}_{6} \mathrm{H}_{4}-p-\mathrm{Br}$ & 1 & 1 & - & 0.25 \\
\hline c $\mathrm{R}=\mathrm{C}_{6} \mathrm{H}_{4}-p-t-\mathrm{Bu}$ & 1 & 1 & 0.2 & - \\
\hline d R $=\mathrm{C}_{6} \mathrm{H}_{4}-m-\mathrm{OCH}_{3}$ & 1.2 & 1 & - & - \\
\hline
\end{tabular}

aReaction conditions: TFAA ( 1.5 equiv), TFA ( 1.55 equiv), indene (6 equiv), $\mathrm{CCl}_{4}$, reflux, $9 \mathrm{~d}$.

isomer $\mathbf{2}^{\prime} \mathbf{b}$, the observed large coupling constant of $14.3 \mathrm{~Hz}$ indicates the trans orientation of $\mathrm{H}-4$ relative to $\mathrm{H}-4 \mathrm{a}$, while in case of isomer 2"'b the proton $\mathrm{H}-4$ appears as a more deshielded doublet with a $7.1 \mathrm{~Hz}$ coupling constant, which is typical for the
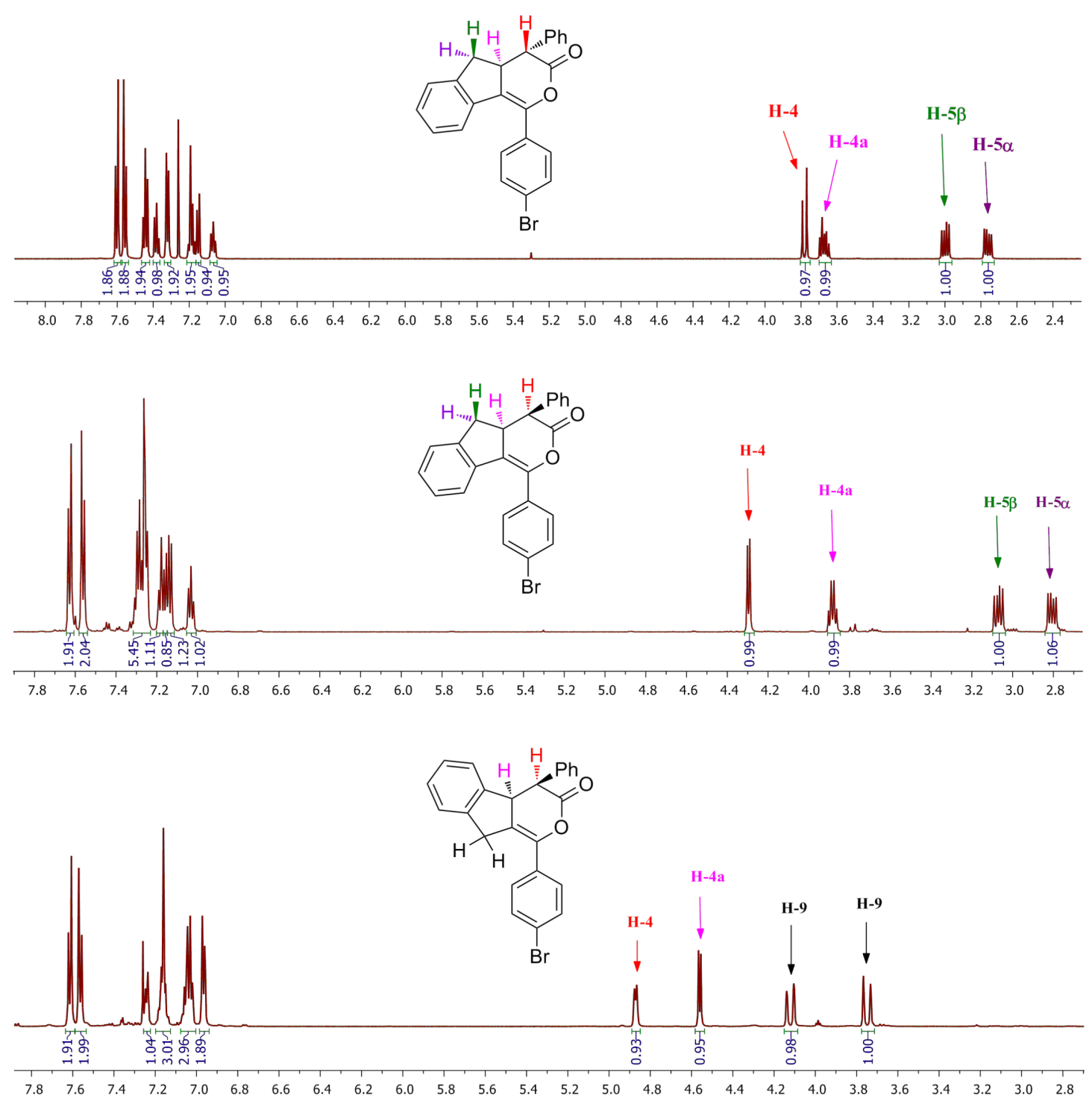

Figure 2: ${ }^{1} \mathrm{H}$ NMR spectra $\left(600 \mathrm{MHz}, \mathrm{CDCl}_{3}\right.$ ) of isomers $\mathbf{2}$ 'b (top), $\mathbf{2}$ "b (middle) and 3"b (bottom). 
cis configuration. The cis configuration was also assigned for diastereoisomer 3"b which displays one doublet at $4.87 \mathrm{ppm}$ for the hydrogen atom at position 4 with a coupling constant of $6.7 \mathrm{~Hz}$.

Generally, the expected structures for all compounds were fully confirmed by the characteristic signals in the ${ }^{1} \mathrm{H}$ NMR spectra (Figure 2). The protons at positions 5 and 9 of compounds 2 or 3 exhibit large coupling constants, typically observed for geminal protons. Noteworthy, in case of isomer 3 'b, the specific methylene protons connected to the enol-lactone moiety display more deshielded signals than those of isomer 2 ''b (Figure 2).

Once the 1,4-disubstituted indenopyrone derivatives were synthesized and their structures confirmed by spectroscopical methods, we further investigated their photophysical properties. No significant differences could be observed in the shape of the electronic bands in the absorption spectra of $\mathbf{2 a -} \mathbf{d}$ recorded in acetonitrile (Figure 3) and methylene chloride (Figure S1, Supporting Information File 1). The spectra exhibit intense broad absorption bands between $275-282 \mathrm{~nm}$ and $307-317 \mathrm{~nm}$, re- spectively, corresponding to $\pi-\pi^{*}$ and $n-\pi^{*}$ transitions. As a general remark, when compared to the reference compound $\mathbf{2 a}$, the maxima of absorption bands for $\mathbf{2 b}-\mathbf{d}$ are slightly redshifted due to the substituents in position 1: $\mathrm{C}_{6} \mathrm{H}_{4}-m-\mathrm{OCH}_{3}$, $\mathrm{C}_{6} \mathrm{H}_{4}-p-t-\mathrm{Bu}$ and $\mathrm{C}_{6} \mathrm{H}_{4}-p-\mathrm{Br}$, respectively (Table 2). The use of methylene chloride or acetonitrile as solvents led to a similar trend of the electronic spectra depending on the nature of the substituents (Table 2, Figure 3, Figure S1 in Supporting Information File 1). However, a slight bathochromic shift could be observed when methylene chloride was used in contrast to a hypsochromic shift in the more polar solvent acetonitrile.

The analysis of the absorption spectra revealed some differences between the regioisomers $\mathbf{2}$ ''b and $\mathbf{3}$ ''b and diastereoisomers 2' and 2", as well (Figure 3, Figure S1, Supporting Information File 1). Thus, a red shift of $35 \mathrm{~nm}$ was observed when comparing the longest wavelength for 2 "'b $\left(\lambda_{\max }=317 \mathrm{~nm}\right)$ with that of its regioisomer 3"'b $\left(\lambda_{\max }=282 \mathrm{~nm}\right)$. This behavior could be explained by an extended electron delocalization in the conjugated system of isomer $2^{\prime \prime} \mathbf{b}$. From the spectra obtained from the diastereoisomers $\mathbf{2}^{\prime}$ and $\mathbf{2}^{\prime \prime}$, one can observe a small shift to higher wavelengths in case of the cis isomers $\mathbf{2}^{\prime \prime}$.
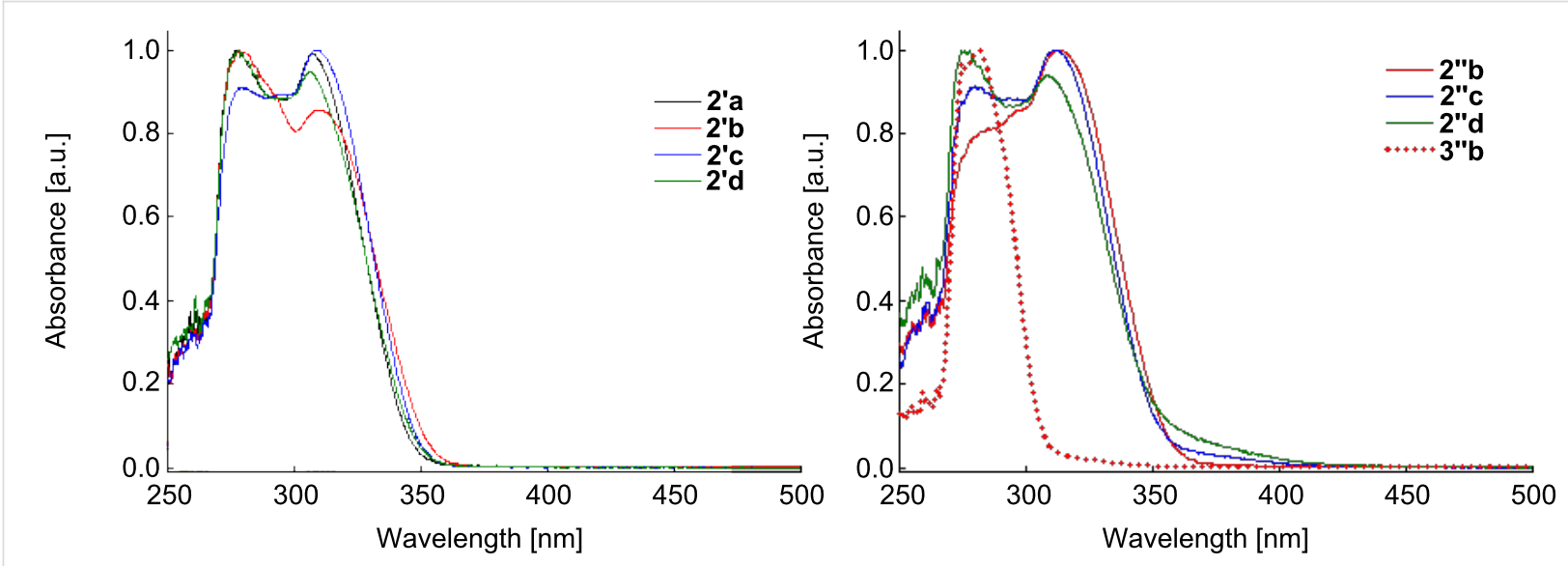

Figure 3: Normalized absorption spectra of dihydroindenopyrones 2'a-d, 2"b-d and 3"b, recorded in acetonitrile (298 K).

Table 2: Absorption data for derivatives $2 a-d$ and 3 "b measured in acetonitrile and methylene chloride at rt.

\begin{tabular}{|c|c|c|c|c|c|c|}
\hline & \multicolumn{3}{|c|}{ Acetonitrile } & \multicolumn{3}{|c|}{ Methylene chloride } \\
\hline & $\lambda_{\text {abs }}(\mathrm{nm})$ & conc. (M) & $\log \varepsilon$ & $\lambda_{\text {abs }}(\mathrm{nm})$ & conc. (M) & $\log \varepsilon$ \\
\hline $2 ' a$ & $278 ; 307$ & 7.3E-05 & $3.95 ; 3.95$ & $280 ; 309$ & $7.45 E-05$ & $3.97 ; 3.99$ \\
\hline $2 ' b$ & $280 ; 310$ & $5.75 \mathrm{E}-05$ & $4.00 ; 3.94$ & $280 ; 315$ & $6.47 \mathrm{E}-05$ & $3.89 ; 3.83$ \\
\hline $2 " b$ & $280 ; 295$ (sh); 313 & 7.81E-05 & $3.80 ; 3.83 ; 3.90$ & $282 ; 295$ (sh); 317 & $7.79 \mathrm{E}-05$ & $3.77 ; 3.82 ; 3.92$ \\
\hline $3 " b$ & $275 ; 282$ & $7.38 \mathrm{E}-05$ & $3.97 ; 3.98$ & $275 ; 282$ & $6.85 E-05$ & $4.05 ; 4.06$ \\
\hline $2 ' c$ & $278 ; 308$ & $8.92 E-05$ & $3.83 ; 3.87$ & 282; 294 (sh); 312 & $6.34 \mathrm{E}-05$ & $3.90 ; 3.91 ; 3.97$ \\
\hline $2 " c$ & $280 ; 312$ & 7.73E-05 & $3.70 ; 3.74$ & $280 ; 294$ (sh); 314 & $7.00 \mathrm{E}-05$ & $3.79 ; 3.80 ; 3.86$ \\
\hline 2'd & $276 ; 307$ & $6.43 \mathrm{E}-05$ & $3.88 ; 3.86$ & $280 ; 309$ & $6.87 E-05$ & $3.84 ; 3.87$ \\
\hline 2"d & $276 ; 309$ & $7.6 \mathrm{E}-05$ & $3.70 ; 3.68$ & $280 ; 311$ & $6.98 \mathrm{E}-05$ & $3.71 ; 3.74$ \\
\hline
\end{tabular}


Moreover, the spectrum of the trans isomer $\mathbf{2}^{\prime} \mathbf{b}$ displays the most intense absorption band at a lower wavelength $(280 \mathrm{~nm})$ in contrast to the cis isomers $\mathbf{2}^{\prime \prime} \mathbf{b}$ (313 nm, in acetonitrile).

All derivatives 2a-d showed an intense emission in acetonitrile in the range 380-393 nm (Figure 4, Table 3), while for the cis isomer 3"'b a weaker emission was observed. This may be explained by a less extended conjugation and an intersystemcrossing process that occurs when an electron is transferred from a singlet energy level into a triplet energy level [36].

The derivatives $\mathbf{2 a}-\mathbf{d}$ are blue emitters, displaying maximumemission bands at around 370-393 nm. Remarkably, the fluorescence quantum yields calculated relative to 9,10-diphenylanthracene are significantly higher in the case of the trans isomers $\mathbf{2}^{\prime}$ as compared to the corresponding cis isomers $2 "$ (Table 3 ).

The solid-state photoluminescence properties of the dihydroindenopyrones $\mathbf{2}$ 'a-c and $\mathbf{2}$ 'a-d were also investigated. These de- rivatives exhibit emission maxima in the range $423-491 \mathrm{~nm}$ when excited at $310 \mathrm{~nm}$ (Figure 5, Table 3).

Comparing the solution (acetonitrile) and solid-state fluorescence spectra of both diastereoisomers (Figure 5), one can observe a bathochromic shift of $\lambda_{\max }$ in the solid state and a broadening of the emission band because of intermolecular interactions.

Next, in order to obtain photoluminescent compounds with higher performance, the dehydrogenation reaction of enollactones $\mathbf{2}$ and $\mathbf{3}$ was performed. Adapted from a procedure previously described [38], the oxidation of the isomeric mixture $\mathbf{2}^{\prime} \mathbf{a} / \mathbf{3}^{\prime \prime} \mathbf{a}$ and $\mathbf{2}^{\prime} \mathbf{c} / \mathbf{3}^{\prime} \mathbf{c}$, respectively, in the presence of 2,3dichloro-5,6-dicyano-1,4-benzoquinone (DDQ), led to indeno$\alpha$-pyrones 4-6 (Scheme 2), in not very satisfying yields.

Investigations carried out for the dehydrogenation reaction of the isomeric mixture 2 'a/3"'a (Scheme 2) revealed the forma-

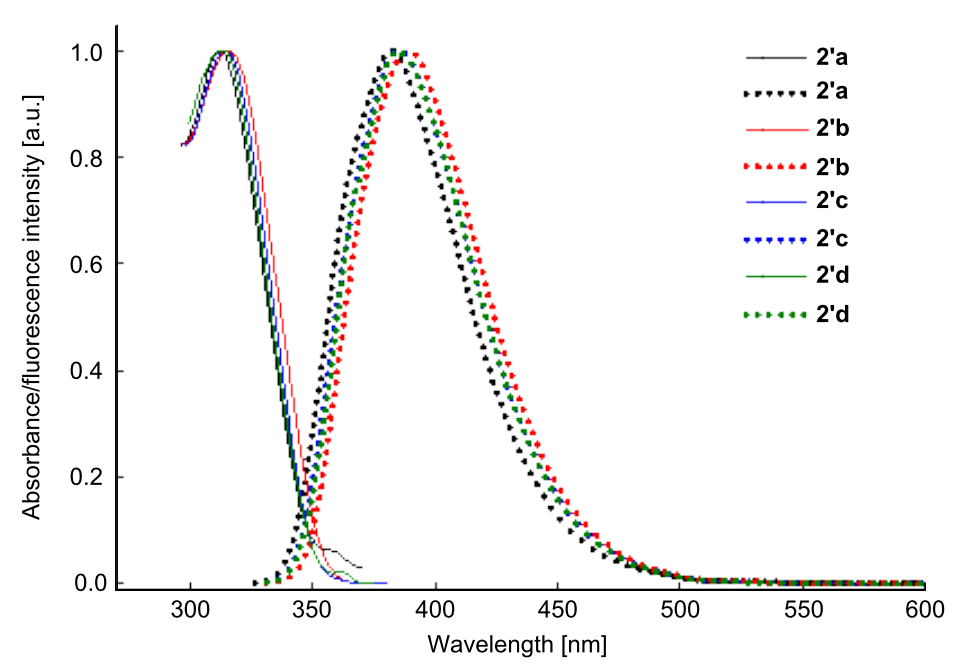

Figure 4: Normalized UV-vis (left) spectra at excitation wavelengths and fluorescence (right) spectra of dihydroindenopyrones 2'a-d.

\begin{tabular}{|c|c|c|c|c|c|}
\hline Compound & Excitation $\lambda[\mathrm{nm}]^{a}$ & Emission $\lambda[\mathrm{nm}]^{\mathrm{a}}$ & Stokes shift $[\mathrm{nm}] /\left[\mathrm{cm}^{-1}\right]$ & Emission $\lambda[\mathrm{nm}]^{\mathrm{b}}$ & $\Phi^{C}$ \\
\hline 2'a & 313 & 382 & $69 / 5771$ & 423 & $7.2 \%$ \\
\hline 2'b & 316 & 389 & $73 / 5939$ & 445 & $18.1 \%$ \\
\hline 2"b & 320 & 393 & $73 / 5805$ & 432 & $5.4 \%$ \\
\hline 3"b & 317 & 390 & $73 / 5905$ & - & $0.3 \%$ \\
\hline 2'c & 315 & 386 & $71 / 5839$ & - & $12.6 \%$ \\
\hline 2"c & 288 & $338 ; 356 ; 370$ & $68 / 6632$ & 475 & $7.2 \%$ \\
\hline 2'd & 313 & 385 & 72 / 5975 & 461 & $10.8 \%$ \\
\hline 2"d & 321 & 389 & $68 / 5446$ & 491 & $3.6 \%$ \\
\hline
\end{tabular}

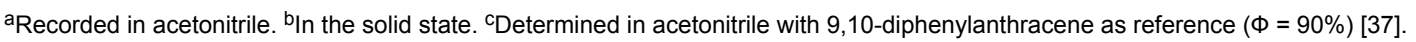




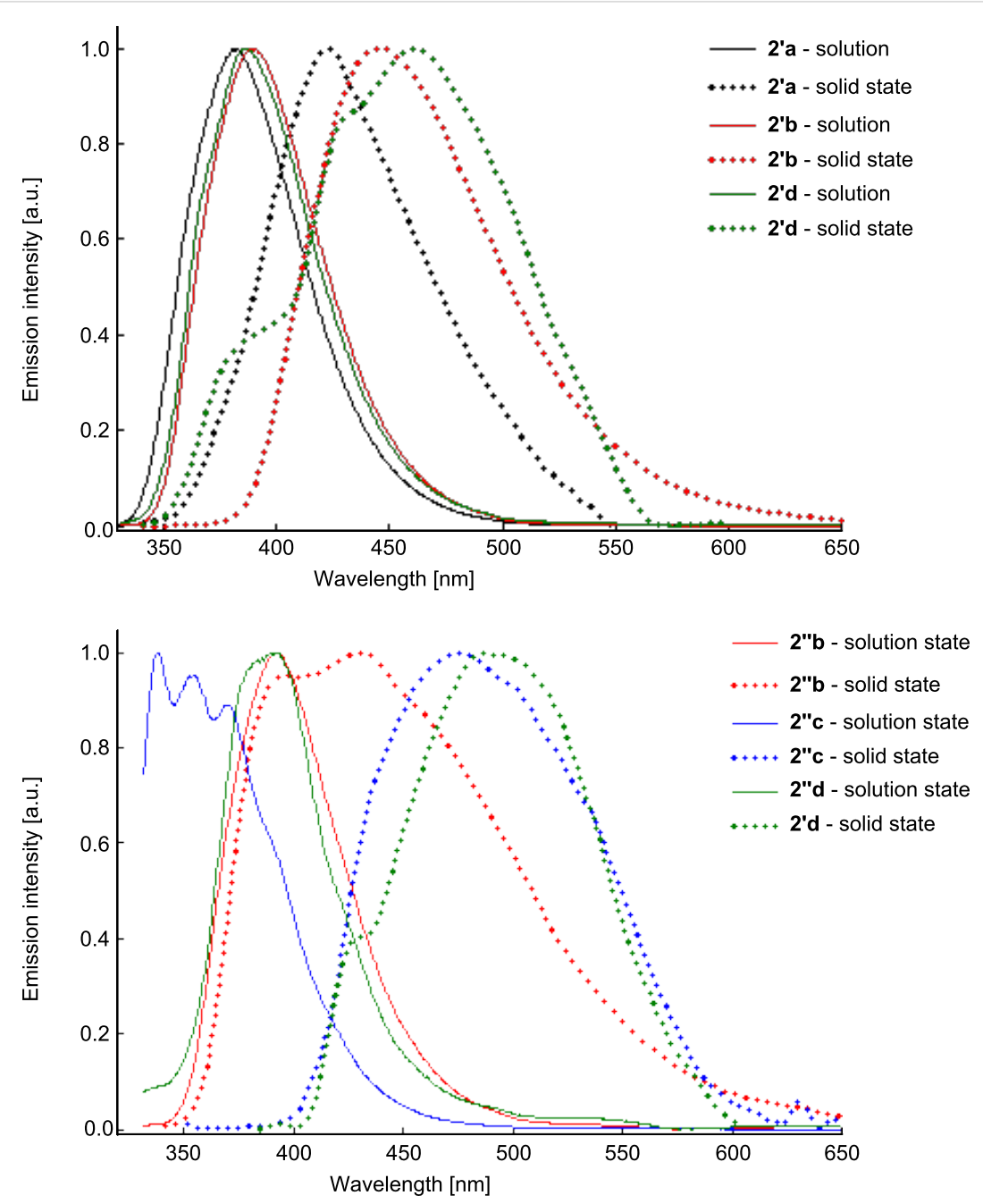

Figure 5: Normalized solid-state and solution (acetonitrile) fluorescence spectra of diastereoisomers $\mathbf{2 a - d . ~}$

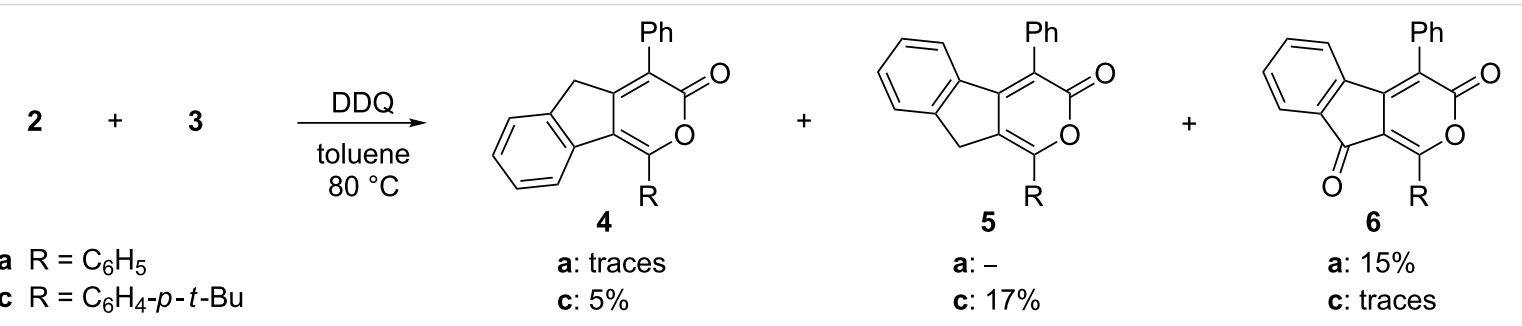

Scheme 2: Synthesis of a-pyrones 4-6.

tion of the $\alpha$-pyrone $6 \mathbf{a}$ ( $15 \%$ yield), which was the oxidation product of isomer 3"a. In the same time, most of the isomer 2'a was recovered and traces of derivative 4 a could only be detected in the NMR spectrum.

Using the same procedure, the enol-lactone isomeric mixture $\mathbf{2}^{\prime} \mathbf{c} / \mathbf{3}$ 'c was subjected to the dehydrogenation reaction yielding the regioisomers $\mathbf{4 c}$ and $\mathbf{5 c}$ (Scheme 2). The ${ }^{1} \mathrm{H}$ NMR spectrum revealed the formation of the fully oxidized derivative $\mathbf{6 c}$ in small amounts that could not be isolated. However, silica gel column chromatography of the reaction mixture allowed the recovery of the starting enol-lactone derivative 2 'c in $50 \%$ yield.

The ${ }^{1} \mathrm{H}$ NMR spectra of $\alpha$-pyrones $\mathbf{4 c}$ and $\mathbf{5 c}$ (Figure S4, Supporting Information File 1) exhibit characteristic signals for the 
aliphatic protons: one singlet at $4.19 \mathrm{ppm}$ for derivative $\mathbf{5 c}$ and one signal at $3.97 \mathrm{ppm}$ for compound $\mathbf{4 c}$, respectively.

Next, the photoluminescence properties of the isolated indenopyrones $4 \mathbf{c}, \mathbf{5 c}$ and $\mathbf{6 a}$ were investigated. The UV-vis spectra (Figure S5, Supporting Information File 1) recorded in methylene chloride displayed two absorption maxima assigned to $\pi-\pi^{*}$ and $n-\pi^{*}$ transitions, respectively. All derivatives showed very weak emission in the range 380-550 nm (Figure S5, Supporting Information File 1) when excited at $370 \mathrm{~nm}$, while the calculated quantum yields relative to 9,10-diphenylanthracene were quite low $(<1 \%)$.

In the crystals of $\alpha$-pyrone $\mathbf{6 a}$, the asymmetric unit consists of a single molecule. The two phenyl rings attached to the pyran-3- one moiety are disposed in a staggered conformation. The angle between the planes defined by the two phenyl rings is $85.8(1)^{\circ}$ and the angle between the non-intersecting $\mathrm{C} 1-\mathrm{C} 13$ and the $\mathrm{C} 3-\mathrm{C} 19$ bond vectors is $12.9(3)^{\circ}$. Both phenyl rings are rotated with respect to the best plane defined through the pyran-3-one moiety $(\mathrm{C} 1-\mathrm{O} 1-\mathrm{C}(2-4)-\mathrm{C} 12)$, with angles of $35.8(2)^{\circ}$ for the (C13-18) ring and $51.1(1)^{\circ}$ for the (C19-24) ring, respectively (Figure 6a).

Several weak, intermolecular $\mathrm{C}-\mathrm{H} \cdots \mathrm{O}$ hydrogen bonds could be identified in the crystal packing (Table S1, Supporting Information File 1). Although the $\mathrm{H} \cdots \mathrm{O}$ distances are close to or greater than the van der Waals limit of $2.60 \AA$ [39], they are still within a range statistically observed for other compounds [40-44]. These $\mathrm{C}-\mathrm{H} \cdots \mathrm{O}$ interactions lead to a first layer of molecules

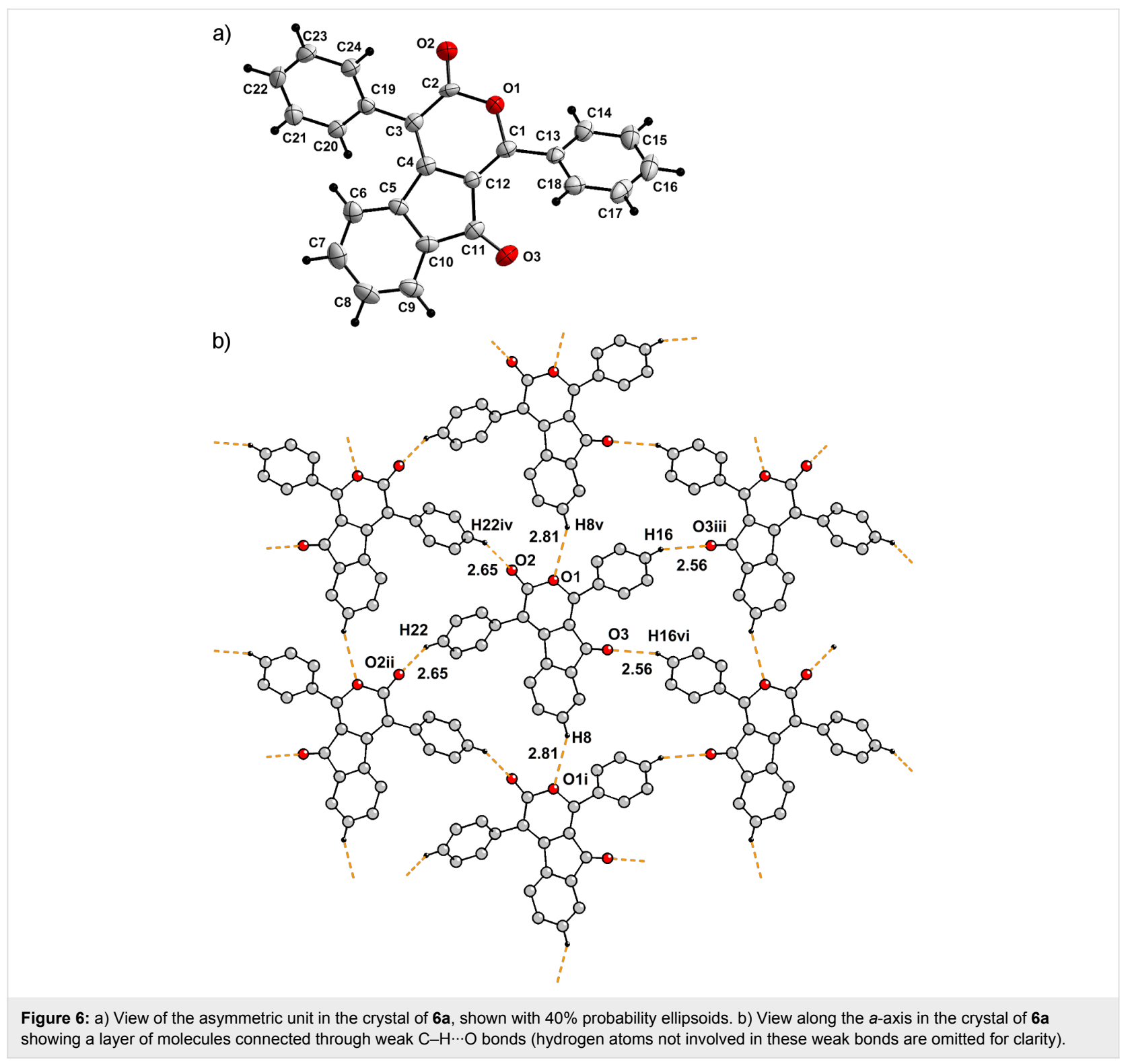


(Figure 6b) with the contribution of $\mathrm{O} 1 \cdots \cdot \mathrm{H} 8, \mathrm{O} 2 \cdots \cdot \mathrm{H} 22$ and O3 $\cdots$ H1 6 bonds. Subsequently, these layers are connected through the weak $\mathrm{O} 2 \cdots \mathrm{H} 15$ and $\mathrm{O} 2 \cdots \mathrm{H} 17$ interactions.

Further edge-to-face $\mathrm{H} \cdots \pi$ [44] and $\pi-\pi$ interactions $[45,46]$ (Table 4) between molecules from neighboring layers contribute to the three-dimensional crystal packing (Figure S6 in Supporting Information File 1).

\section{Conclusion}

Several indenopyrone derivatives were synthesized and characterized by NMR, UV-vis and fluorescence spectroscopy as well as mass spectrometry. Column chromatography of the crude product furnished the diastereoisomers as pure samples. The electronic spectra display two intense absorption bands ranging between $275-282 \mathrm{~nm}$ and $307-317 \mathrm{~nm}$, while their photoluminescence spectra revealed that all compounds are blue emitters.

The calculated fluorescence quantum yield relative to 9,10diphenylanthracene is significantly higher for the trans isomers when compared to the corresponding cis isomers. The solidstate fluorescence investigations revealed in the case of the regioisomers 2 a bathochromic shift together with an emissionband broadening in contrast to their emission spectra recorded in solution. The supramolecular arrangement in the solid state of indenopyrone $\mathbf{6 a}$ is ensured by a number of non-covalent interactions such as intermolecular $\mathrm{H}$-bonding, $\mathrm{C}-\mathrm{H} \cdots \pi$ and $\pi \cdots \pi$ contacts.

\section{Supporting Information}

\section{Supporting Information File 1}

Experimental.

[http://www.beilstein-journals.org/bjoc/content/

supplementary/1860-5397-12-81-S1.pdf]

\section{Acknowledgements}

Financial support by the National Research Council (CNCS) of Romania, project PN-II_ID-PCCE-2011-2-0069 is gratefully acknowledged. A. Ţepeş thanks to Babeş-Bolyai University for a one-year scholarship.

\section{References}

1. Goulart, M. O. F.; Santana, A. E. G.; de Oliveira, A. B.; de Oliveira, G. G.; Maia, J. G. S. Phytochemistry 1986, 25, 1691-1695. doi:10.1016/S0031-9422(00)81237-6

2. Balaña-Fouce, R.; Prada, C. F.; Requena, J. M.; Cushman, M.; Pommier, Y.; Álvarez-Velilla, R.; Escudero-Martínez, J. M.; Calvo-Álvarez, E.; Pérez-Pertejo, Y.; Reguera, R. M. Antimicrob. Agents Chemother. 2012, 56, 5264-5270. doi:10.1128/AAC.00499-12

3. Suryavanshi, J. P.; Pai, N. R. Indian J. Chem., Sect. B 2006, 45, 1227-1230.

4. Thi, T. P.; Decuyper, L.; Quang, T. L.; The, C. P.; Dang Thi, T. A.; Nguyen, H. T.; Le Nhat, T. G.; Thanh, T. N.; Thi, P. H.; D'hooghe, M.; Van Nguyen, T. Tetrahedron Lett. 2016, 57, 466-471. doi:10.1016/j.tetlet.2015.12.045

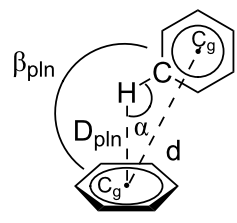

\begin{tabular}{llll}
\hline & & $\mathrm{C}-\mathrm{H} \cdots \pi$ interactions & $\beta_{\mathrm{pln}}\left({ }^{\circ}\right)$ \\
$\mathrm{C}-\mathrm{H} \cdots \mathrm{pln}$ & $\mathrm{D}_{\mathrm{pln}}(\AA)$ & $\alpha\left(^{\circ}\right)$ & 85.8 \\
$\mathrm{C} 20-\mathrm{H} 20 \cdots \mathrm{C}(13-18)^{\mathrm{a}}$ & 2.93 & 116 & 78.7 \\
$\mathrm{C} 18-\mathrm{H} 18 \cdots \mathrm{C}(19-24)^{\mathrm{b}}$ & 2.95 & 109 & 39.5 \\
$\mathrm{C} 14-\mathrm{H} 14 \cdots \mathrm{C}(5-10)^{\mathrm{a}}$ & 2.79 & 143 & \\
\hline & & $\pi \cdots \pi$ interactions & \\
\hline $\mathrm{pln} \cdots \mathrm{pln}$ & & & $\beta_{\mathrm{pln}}\left({ }^{\circ}\right)$ \\
$\mathrm{C}(4-12) \cdots \mathrm{C}(4-12)^{\mathrm{a}}$ & $\mathrm{d}(\AA)$ & & 0 within s.d. \\
$\mathrm{C}(4-12) \cdots \mathrm{C}(4-12)^{\mathrm{b}}$ & 3.52 & & 0 within s.d. \\
\hline
\end{tabular}

aSymmetry equivalent atoms are given by $-x, 1-y,-z$. bSymmetry equivalent atoms are given by (ii) $1-x, 1-y,-z$. 
5. Kohlhagen, G.; Paull, K. D.; Cushman, M.; Nagafuji, P.; Pommier, Y. Mol. Pharmacol. 1998, 54, 50-58.

6. Beck, D. E.; Agama, K.; Marchand, C.; Chergui, A.; Pommier, Y.; Cushman, M. J. Med. Chem. 2014, 57, 1495-1512. doi:10.1021/jm401814y

7. Lv, P.-C.; Agama, K.; Marchand, C.; Pommier, Y.; Cushman, M. J. Med. Chem. 2014, 57, 4324-4336. doi:10.1021/jm500294a

8. Yang, R.-Y.; Kizer, D.; Wu, H.; Volckova, E.; Miao, X.-S.; Ali, S. M.; Tandon, M.; Savage, R. E.; Chan, T. C. K.; Ashwell, M. A. Bioorg. Med. Chem. 2008, 16, 5635-5643. doi:10.1016/j.bmc.2008.03.073

9. Kung, H.-N.; Lu, K.-S.; Chau, Y.-P. Chemotherapy 2014, 3, 131. doi:10.4172/2167-7700.1000131

10. Thasana, N.; Ruchirawat, S. Tetrahedron Lett. 2002, 43, 4515-4517. doi:10.1016/S0040-4039(02)00818-3

11. Gaber, A. A. A. Sens. Actuators, B 2003, 96, 615-620. doi:10.1016/j.snb.2003.07.004

12. Coelho, P. J.; Salvador, M. A.; Oliveira, M. M.; Carvalho, L. M. Tetrahedron 2004, 60, 2593-2599. doi:10.1016/j.tet.2004.01.034

13. Berthet, J.; Coelho, P. J.; Carvalho, L. M.; Vermeerscha, G.; Delbaere, S. J. Photochem. Photobiol., A: Chem. 2009, 208, 180-185. doi:10.1016/j.jphotochem.2009.09.013

14. Chen, C.-T. Chem. Mater. 2004, 16, 4389-4400. doi:10.1021/cm049679m

15. Yao, Y.-S.; Zhou, Q.-X.; Wang, X.-S.; Wang, Y.; Zhang, B.-W. Adv. Funct. Mater. 2007, 17, 93-100. doi:10.1002/adfm.200600055

16. Liu, T.-H.; lou, C.-Y.; Chen, C. H. Appl. Phys. Lett. 2003, 83, 5241-5243. doi:10.1063/1.1635986

17. Zhao, P.; Tang, H.; Zhang, Q.; Pi, Y.; Xu, M.; Sun, R.; Zhu, W. Dyes Pigm. 2009, 82, 316-321. doi:10.1016/j.dyepig.2009.01.016

18. Zhang, X. H.; Chen, B. J.; Lin, X. Q.; Wong, O. Y.; Lee, C. S.; Kwong, H. L.; Lee, S. T.; Wu, S. K. Chem. Mater. 2001, 13, 1565-1569. doi:10.1021/cm0008664

19. Yang, L.; Guan, M.; Nie, D.; Lou, B.; Liu, Z.; Bian, Z.; Bian, J.; Huang, C. Opt. Mater. 2007, 29, 1672-1679. doi:10.1016/j.optmat.2006.09.013

20. Hagimori, M.; Mizuyama, N.; Yokota, K.; Nishimura, Y.; Suzuta, M.; Tai, C.-K.; Wang, B.-C.; Wang, S.-L.; Shih, T.-L.; Wu, K.-D.; Huang, Z.-S.; Tseng, S.-C.; Chen, C.-Y.; Lu, J.-W.; Wei, H.-H.; Kawashima, K.; Kawashima, S.; Tominaga, Y. Dyes Pigm. 2012, 92, 1069-1074. doi:10.1016/j.dyepig.2011.05.014

21. Shahrisa, A.; Safa, K. D.; Esmati, S. Spectrochim. Acta, Part A 2014, 117, 614-621. doi:10.1016/j.saa.2013.09.056

22. Leung, M.-k.; Chang, C.-C.; Wu, M.-H.; Chuang, K.-H.; Lee, J.-H.; Shieh, S.-J.; Lin, S.-C.; Chiu, C.-F. Org. Lett. 2006, 8, 2623-2626. doi:10.1021/ol060803c

23. Wang, S.; Qi, Q.; Li, C.; Ding, G.; Kim, S.-H. Dyes Pigm. 2011, 89, 188-192. doi:10.1016/j.dyepig.2010.09.010

24. Zhu, W.; Huang, X.; Guo, Z.; Wu, X.; Yu, H.; Tian, H. Chem. Commun. 2012, 48, 1784-1786. doi:10.1039/c2cc16902a

25. Li, M.; Wu, X.; Wang, Y.; Li, Y.; Zhu, W.; James, T. D. Chem. Commun. 2014, 50, 1751-1753. doi:10.1039/c3cc48128j

26. Guo, Z.; Zhu, W.; Tian, H. Chem. Commun. 2012, 48, 6073-6084. doi:10.1039/c2cc31581e

27. Usachev, S. A.; Usachev, B. I.; Sosnovskikh, V. Ya. Tetrahedron 2014, 70, 60-66. doi:10.1016/j.tet.2013.11.033

28. Petrzilka, M.; Grayson, J. I. Synthesis 1981, 753-786. doi:10.1055/s-1981-29592
29. Tintas, M. L.; Diac, A. P.; Soran, A.; Terec, A.; Grosu, I.; Bogdan, E. J. Mol. Struct. 2014, 1058, 106-113. doi:10.1016/j.molstruc.2013.11.005

30. Mertelmeyer, S. a-Pyrone und Cyclopenta[c]pyrane aus

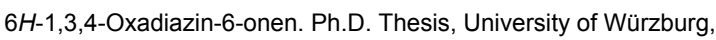
Germany, 1997.

31. Hegmann, J.; Ditterich, E.; Hüttner, G.; Christl, M.; Peters, E.-M.; Peters, K.; von Schnering, H. G. Chem. Ber. 1992, 125, 1913-1918. doi:10.1002/cber.19921250819

32. Tidwell, T. T.; Sammtleben, F.; Christl, M. J. Chem. Soc., Perkin Trans. 1 1998, 2031-2035. doi:10.1039/a802364f

33. Sauer, J.; Sustmann, R. Angew. Chem., Int. Ed. Engl. 1980, 19, 779-807. doi:10.1002/anie.198007791

34. Christl, M. Gazz. Chim. Ital. 1986, 116, 1-17.

35. Christl, M.; Bien, N.; Bodenschatz, G.; Feineis, E.; Hegmann, J.; Hofmann, C.; Mertelmeyer, S.; Ostheimer, J.; Sammtleben, F.; Wehner, S.; Peters, E.-M.; Peters, K.; Pfeiffer, M.; Stalke, D. Chem. Commun. 1998, 2387-2388. doi:10.1039/a807233g

36. Karatay, A.; Miser, M. C.; Cui, X.; Küçüköz, B.; Yılmaz, H.; Sevinç, G.; Akhüseyin, E.; Wu, X.; Hayvali, M.; Yaglioglu, H. G.; Zhao, J.; Elmali, A. Dyes Pigm. 2015, 122, 286-294. doi:10.1016/j.dyepig.2015.07.002

37. Brouwer, A. M. Pure Appl. Chem. 2011, 83, 2213-2228. doi:10.1351/PAC-REP-10-09-31

38. Li, C. J.; Li, Y.-Z.; Pinto, A. V.; Pardee, A. B. Proc. Natl. Acad. Sci. U. S. A. 1999, 96, 13369-13374. doi:10.1073/pnas.96.23.13369

39. Emsley, J. Die Elemente; Walter de Gruyter: Berlin, Germany, 1994 doi:10.1515/9783110857054

40. Desiraju, G. R. Acc. Chem. Res. 1991, 24, 290-296. doi:10.1021/ar00010a002

41. Desiraju, G. R. Acc. Chem. Res. 1996, 29, 441-449. doi:10.1021/ar950135n

42. Steiner, T. Crystallogr. Rev. 1996, 6, 1-57. doi:10.1080/08893119608035394

43. Steiner, T. Chem. Commun. 1997, 727-734. doi:10.1039/a603049a

44. Desiraju, G. R.; Steiner, T. The Weak Hydrogen Bond in Structural Chemistry and Biology; Oxford University Press: Oxford, United Kingdom, 1999.

45. Hunter, C. A.; Sanders, J. K. M. J. Am. Chem. Soc. 1990, 112, 5525-5534. doi:10.1021/ja00170a016

46. Janiak, C. J. Chem. Soc., Dalton Trans. 2000, 21, 3885-3896. doi:10.1039/b003010o 


\section{License and Terms}

This is an Open Access article under the terms of the Creative Commons Attribution License

(http://creativecommons.org/licenses/by/2.0), which permits unrestricted use, distribution, and reproduction in any medium, provided the original work is properly cited.

The license is subject to the Beilstein Journal of Organic Chemistry terms and conditions:

(http://www.beilstein-journals.org/bjoc)

The definitive version of this article is the electronic one which can be found at:

doi:10.3762/bjoc. 12.81 